\title{
Decline in the alpine landscape aesthetic value in a national park under climate change
}

\author{
Kota Mameno $^{1}$ (D) Takahiro Kubo $^{2,3,4}$ (D) Hiroyuki Oguma ${ }^{2}$ Yukihiro Amagai $^{5}$. \\ Yasushi Shoji ${ }^{6}$ (D)
}

Received: 13 September 2021 / Accepted: 30 January 2022 / Published online: 19 February 2022

(c) The Author(s) 2022

\begin{abstract}
Alpine landscapes are projected to be degraded under climate change, which would threaten their benefits to society. Previous studies, however, have been limited to aesthetic change, and it remains unclear how much the aesthetic change would affect human welfare. To address this issue and gain insights into climate change adaptation policies, we conducted a choice experiment survey using digitally manipulated images based on climate change scenarios and natural scientific knowledge in a mountainous national park in Japan. We uncovered that park visitors appreciate the alpine landscapes that include snow patches on mountains and some types of alpine flowers by analyzing the data from 445 respondents. Conversely, both the invasion of alpine vegetation by dwarf bamboo and the disappearance of snow patches due to climate change substantially deteriorated the perceived aesthetic benefits from alpine landscapes. The economic loss caused by climate-induced landscape degradation was estimated at more than 100 USD per visitor, at maximum; the disappearance of snow patches and invasion by dwarf bamboo reduced the benefits by approximately 13 USD and 101 USD, respectively. Our findings suggest that sustaining the aesthetic value of alpine landscapes in national parks via climate change adaptation has potentially significant economic benefits. By supposing that the mountain national park attracts 70,000 visitors in summer, climate change would cause as a minimum of eight million USD economic loss at the park without appropriate measures annually. Our findings highlight the importance of climate change measures by considering climate change impacts on social benefits associated with alpine landscapes.
\end{abstract}

Keywords Alpine vegetation - Climate change adaptation - Cultural ecosystem service · Discrete choice experiment $\cdot$ Mountainous national park

Kota Mameno

kota.mameno@gmail.com

Extended author information available on the last page of the article 


\section{Introduction}

Alpine ecosystems are vulnerable to climate change (Chen et al. 2013; Crowther et al. 2016). Global warming and decreasing snow seasons make alpine plant propagation difficult due to the decline in unique environments suitable for alpine plants (Gottfried et al. 2012; Kudo et al. 2011; Wessely et al. 2022). Climate change also leads to rapid glacier retreat and loss of snow coverage (Cullen et al. 2013). That leads to landscape changes (Schirpke et al. 2013). Such landscape change is a substantial concern not only from a natural science viewpoint but also from social and economic perspectives (Scott et al. 2007; Stern et al. 2006). For instance, glacier retreat has changed the scenic landscape to such an extent that tourism demand has declined (Hall and Fagre 2003; Wang and Zhou 2019), and these negative impacts have affected at least 50 glacier tourism destinations (Scott et al. 2007; Wang et al. 2010). Therefore, to develop effective climate change adaptation strategies that will minimize the negative impacts on society, it is essential to understand the current values of alpine landscapes and project the future values under climate change (Gössling et al. 2012; Scott et al. 2012).

To develop adaptation policies under climate change, it is required to assess human well-being in monetary terms to support policy decision-making (Folkersen 2018; Kubo et al. 2020), which should also be applied to alpine ecosystems. However, previous monetary valuation studies focused on human-influenced landscapes, such as traditional agricultural lands. Fleischer and Sternberg (2006), for example, found that Israeli residents appraised the rangelands landscape with high value and were willing to pay about 80 million USD for its conservation, which is higher than the value of its grazing services. While using a discrete choice experiment with digitally manipulated images of the Swiss Alps, Rewitzer et al. (2017) found that forest expansion due to climate change has negative impacts on local stakeholder's willingness to pay (WTP) for a cultural landscape; moreover, they also demonstrated that respondents preferred agricultural heritage landscapes and biodiversity-rich grasslands, and their WTP for the grassland was about 300 EUR per person per year. Despite that the economic value of a landscape varies significantly based on landscape components and quality (Howley 2011; Molina et al. 2016), there have been no monetary valuation studies addressing the change in the aesthetic value of natural alpine landscapes (Ignacio 2017; Martín-López et al. 2019).

To address this knowledge gap, this study applied a monetary valuation method using digitally manipulated images with referring to previous studies evaluating aesthetic ecosystem services (Graves et al. 2017; Rewitzer et al. 2017; van Berkel and Verburg 2014). There have been a few valuation studies on the effects of climate change on ecosystem services associated with landscapes. However, they did not identify how much the aesthetic benefits contributed to the entire value. Therefore, our study attempts to evaluate the aesthetic value associated with alpine landscapes by sincerely designing an image-based survey with reference to previous studies (Graves et al. 2017; Rewitzer et al. 2017; van Berkel and Verburg 2014). An image-based choice experiment is informative for respondents and can be suitable to elicit preference for landscape attributes more than a textbased choice experiment although there is a risk of providing unintentional information to respondents with an image-based survey (Bateman et al. 2009; Hsee 1996; Shr et al. 2019). This study applied an image-based choice experiment survey to a Japanese alpine national park, Daisetsuzan National Park, which is facing a climate change crisis (Yokohata et al. 2021). Across the world, national parks are well recognized as areas providing recreational opportunities as well as habitat for wildlife; however, the monetary value of their aesthetic 
attributes have remained unclear. To explore these values, we developed an image-based choice experiment survey concerning alpine vegetation and the amount of snow remaining on mountains by using information from previous ecological climate change studies predicting their changes (e.g., Amagai et al. 2018). Our findings may help to enhance public support for adaptation strategies by demonstrating the monetary values of the parks' aesthetic attributes.

\subsection{Daisetsuzan National Park under climate change}

The choice experiment survey was carried out at Mount Asahidake (2291m elevation) in Daisetsuzan National Park, northern Japan (Fig. 1a, b). The park is the largest among Japan's national parks and receives approximately 5 million visitors annually because of its unique landscapes and ecosystems (Ministry of Environment 2021); of them, approximately $0.07-0.1$ million visitors visit in summer (i.e., from June to October) according to the data counting visitor in trail entry points (Ministry of Environment 2021). In summer, for example, visitors are drawn to the blooming alpine flowers and permanent snow on the mountain (Fig. 1c).

However, such aesthetic attractions would be degraded by climate change. A previous study conducted in the park identified an increase in the annual average temperature from 1980 to 2010 and an advancement of the snow thawing season from 1988 to 2012 (Amagai et al. 2018). A case study projected that permafrost, which contributes to the growth of alpine flowers, will decrease to one-tenth in Daisetsuzan National Park under the RCP 2.6 scenario (van Vuuren et al. 2011; Yokohata et al. 2021). Furthermore, long-term monitoring over the last few decades found expansion of the distribution of dwarf shrubs and dwarf bamboo and a decline in the dominance of forbs (Amagai et al. 2015; Amagai et al. 2018; Kudo et al. 2011). These changes highlight the importance of climate change mitigation and adaptation strategies from both biological and ecological perspectives (Kudo et al. 2017).

(a)

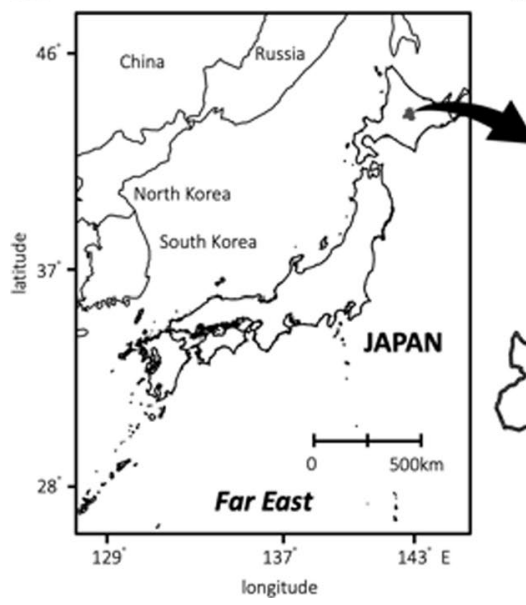

(b)

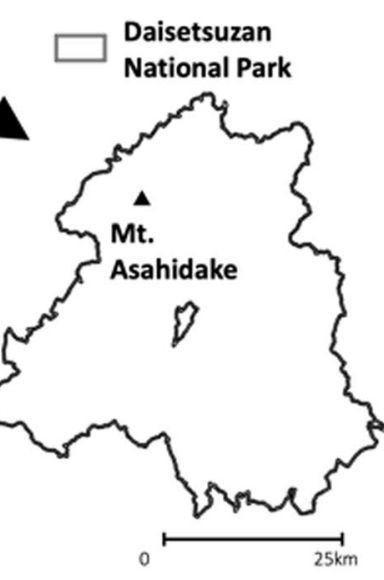

(c)
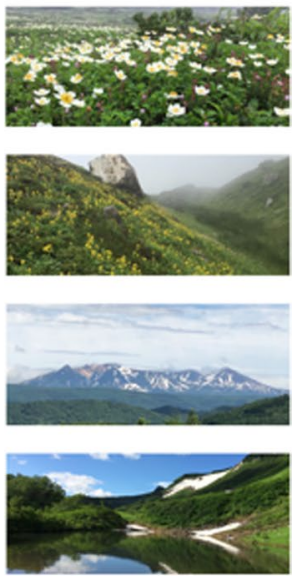

Fig. 1 The study site, Daisetsuzan National Park, in northern Japan. a Location of the study site. b Location of Mount Asahidake in the park. c Examples of alpine landscapes in the national park 
Adaptation action toward climate change is in its early stages and is challenging in national parks. Initial attempts revealed that the removal of dwarf bamboo to conserve alpine vegetation in Daisetsuzan National Park resulted in the recovery of biodiversity in the area over 6 years (Kudo et al. 2017). Although our ecological knowledge of the park has improved, the impacts of climate change and adaptation strategies on the park's social and economic benefits have yet to be clarified.

\section{Material and methods}

\subsection{Survey design}

We designed a choice experiment survey based on the ecological knowledge about climate change affects alpine vegetation and the interviews conducted on local environmental managers. We designed the choice experiment profile with the three attributes with reference to the previous studies that stated that it is desirable to utilize the minimum number of attributes to reduce the burden of answering the choice experiment (e.g., Hanley and Czajkowski 2019; Holmes and Adamowicz 2003; Swait and Adamowicz 2001; Watson et al. 2017): (1) the existence of snow patches; (2) the state of alpine vegetation and invasion by dwarf bamboo; and (3) the management of fees (i.e., cooperative funds) to provide for the implementation of climate change adaptation measures (Table 1). Moreover, given the discussion with the park managers, our choice experiment profile was designed based on the image that mainly included three attributes that also reduce the response burden for visitors at the national park.

The existence of snow patches was divided into two levels: absent or present. The state of alpine vegetation was divided into five levels: dwarf bamboo only; alpine vegetation without flowers; and one, two, or three plant species with flowers. These levels were selected based on the following climate change scenarios: perpetual decline of snow patches due to temperature rise (Amagai et al. 2018; Kudo 2014; Kudo and Hirao 2006); an increase in dwarf bamboo at higher elevations (Kudo et al. 2011; Winkler et al. 2016); and a decrease in popular alpine plant species (Amagai et al. 2018). After considering the aesthetic landscape associated with flowers (Graves et al. 2017), three alpine flower colors (white, pink, and yellow) were selected for use in a manipulated image (Fig. 2). The whiteflowered species (Anemone narcrissiflora var. sachalinensis) is the most vulnerable of the three, the pink-flowered one (Primula cuneifolia) is less vulnerable than the white-flowered species but its habitat is limited, and the yellow-flowered plant (Potentilla matsumurae) is as vulnerable as the pink-flowered one but it has a wide habitat (Amagai et al. 2018;

Table 1 Attributes and levels for profile design using the choice experiment

\begin{tabular}{ll}
\hline Attribute & Level \\
\hline Snow patches & Absent; present \\
Alpine vegetation & Dwarf bamboo only; alpine vegetation without flowers; one plant \\
& species with flowers; two plant species with flowers; three plant \\
& species with flowers \\
Management fee (cooperative funds) & $0 ; 500 ; 1500 ; 3000 ; 5000 \mathrm{JPY}(0 ; 5 ; 15 ; 30 ; 50$ USD, respectively) \\
\hline
\end{tabular}

JPY was used as the monetary unit for the management fee on the original questionnaire 


\begin{abstract}
You can enjoy the amazing view in the Daisetsuzan National Park during the summer. However, it is predicted that the aesthetic landscape of Mt. Daisetsuzan will change substantially due to climate change in the future. If no actions are taken to cope with climate change, it is predicted that the snow ridge will disappear on the mountain in 2050. Furthermore, the alpine plants will also disappear, and the land will be covered with bamboo grass. However, the impacts can be mitigated by adaptation to climate change.
\end{abstract}
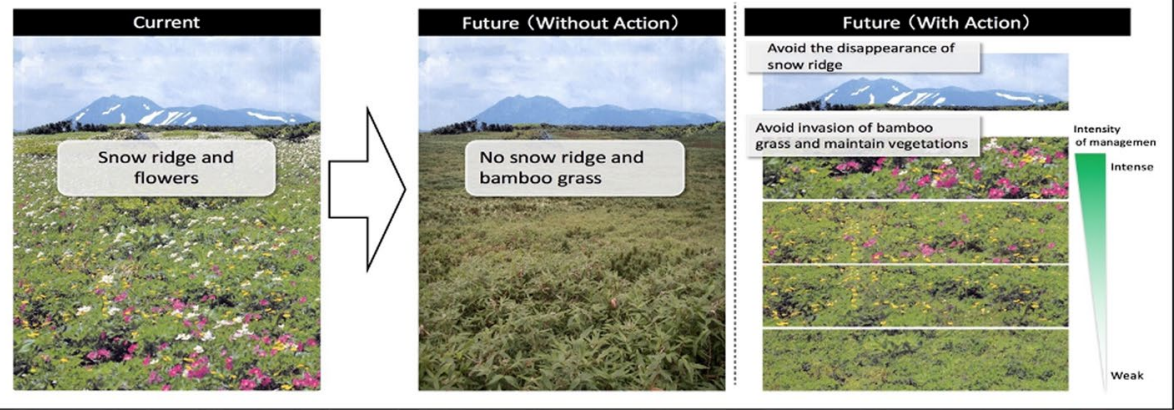

Fig. 2 A scenario presented to respondents in this study

Hirao and Kudo 2008; Shimono et al. 2009). In the present study, it was assumed that these flower species were disappearing in the following order: white, pink, and yellow. Finally, the attribute of the management fee was divided into five levels: 0, 500, 1500, 3000, and $5000 \mathrm{JPY}(0,5,15,30$, and $50 \mathrm{USD}$, respectively). The level of the management fee attribute was decided with reference to the interview survey conducted on the park managers and the previously stated preference and donation studies conducted in the Daisetsuzan National Park (e.g., Kubo and Shoji 2016; Kubo et al. 2018). A one-time voluntary donation was assumed a way to pay the management fee in our choice scenario. This is because, in practice, environmental and park managers often apply voluntary donations rather than mandatory fees to collect management fees for Japanese national parks.

The survey applied the D-efficiency experimental design with 25 choice sets split into five blocks (i.e., five choice sets per respondent), which was developed using the Ngene software (Choice Metrics Pty Ltd, Sydney, Australia). The experimental design has benefits in terms of the robustness of design and reliability of estimated parameters; for example, this design can minimize the distribution of estimated parameters, which contributes to efficient parameter estimation (see Bliemer et al. 2009; Hensher et al. 2015; Huber and Zwerina 1996). To imitate the actual management choice situations (Kamakura et al. 2001), choice sets that comprised "no adaptive management of alpine environments" and two selected profiles were created. Five versions of the questionnaire with five choice sets each were created, and each respondent was provided with one randomly selected questionnaire (Fig. 3).

\title{
2.2 Sampling and data
}

A questionnaire survey was distributed to park visitors at a trailhead on Mount Asahidake in August 2018. A total of 1201 questionnaires were randomly distributed, and 451 responses were returned by mail. Before answering the questions, potential participants were provided with a statement about the use of the collected data and protection of their 


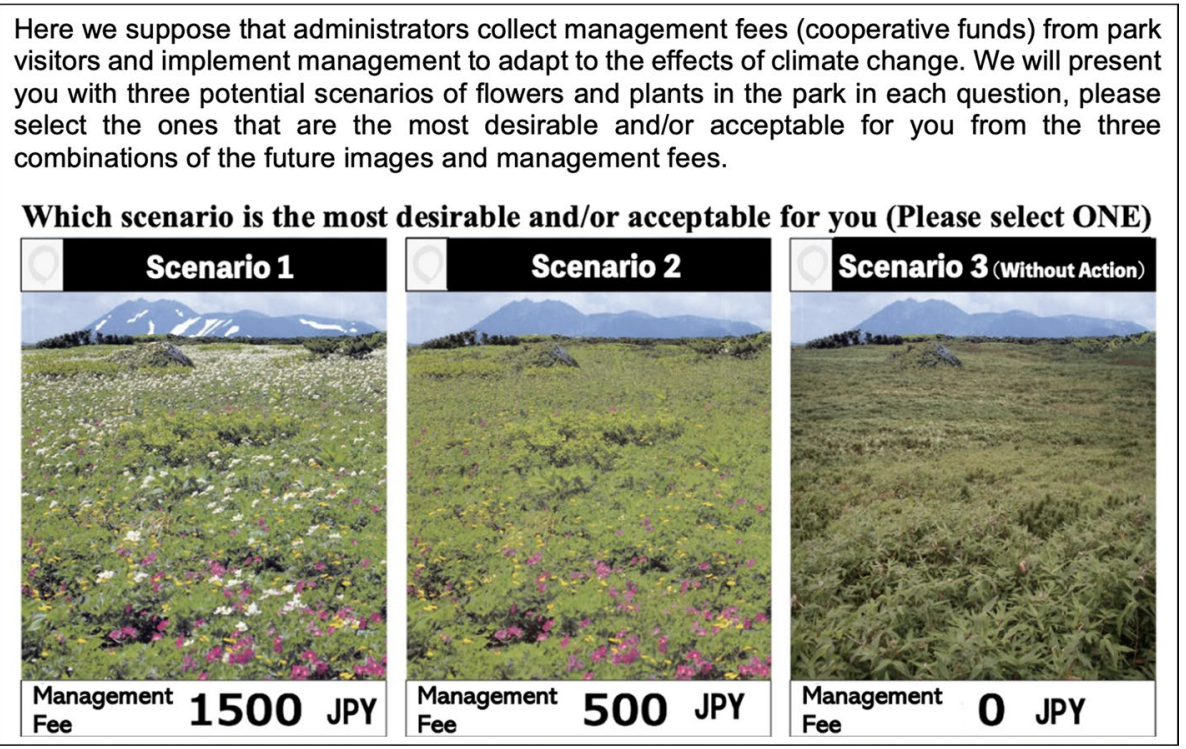

Fig. 3 Example of a choice set in the questionnaire. Three profiles were presented to each respondent: two profiles with different levels for the four attributes and one no-action profile. $100 \mathrm{JPY}$ equals about 1 USD (i.e., 3000 and 500 JPY are 30 and 5 USD, respectively). Although Fig. 3 shows a profile of "three kinds of flowers, snow, and 1500 JPY," our choice sets also include other profiles such as "three kinds of flowers, snow, and 5000 JPY." Of these, there are unrealistic options; however, the inclusion of unrealistic options is not a serious issue in the choice experiment owing to the analysis based on choice behaviors

personal information, noting that we were collecting responses anonymously; only those who agreed with the policy were included in the study.

After excluding non-answered to CE questions, data were analyzed based on 2201 choice sets and relevant data from 445 respondents. Table 2 gives a summary of the respondents' characteristics, including sex, age, education level, and experience visiting the park. Half of the respondents identified themselves as female, and the representative

Table 2 Sample characteristics $(n=445)$

\begin{tabular}{lc}
\hline Characteristics & $(n ; \%)$ \\
\hline Sex & Male $(195 ; 43.8 \%)$, female $(193 ; 43.3 \%)$ \\
Age & $10 \mathrm{~s}(4 ; 0.9 \%), 20 \mathrm{~s}(21 ; 4.7 \%), 30 \mathrm{~s}(51 ; 11.5 \%), 40 \mathrm{~s}(104 ; 23.4 \%), 50 \mathrm{~s}$ \\
& $(114 ; 25.6 \%), 60 \mathrm{~s}(102 ; 22.9 \%), 70 \mathrm{~s}(31 ; 7.0 \%), 80 \mathrm{~s}(2 ; 0.4 \%)$ \\
Education level & Junior high school $(5 ; 1.1 \%)$, senior high school $(86 ; 19.3 \%)$, post-second- \\
& ary technical school $(34 ; 7.6 \%)$, college graduate or diploma $(37 ; 8.3 \%)$, \\
& university undergraduate graduate $(218 ; 49.0 \%)$, master's degree $(28 ;$ \\
& $6.3 \%)$, PhD degree $(13 ; 2.9 \%)$, other $(5 ; 1.1 \%)$
\end{tabular}

Experience of visiting Daiset- First time (294; 66.1\%), second time and above $(149,33.5 \%)$ suzan National Park

Since the responses include missing values, the percentage points do not sum to 100 
age groups were those in their $40 \mathrm{~s}(23.4 \%), 50 \mathrm{~s}$ (25.6\%), and $60 \mathrm{~s}(22.9 \%)$. One-third $(149 ; 33.5 \%)$ of the respondents had visited the park before. The characteristics of our sample were similar to some previous studies conducted in the Daisetsuzan National Park (e.g., Kubo and Shoji 2016; Kubo et al. 2018), which can imply that our sample represents the population of summer visitors to the Daisetsuzan National Park.

\subsection{Analysis}

To assess aesthetic values of the alpine landscape, we applied a mixed logit model (Revelt and Train 1998), which has the advantages of approximating any random utility model and addressing preference heterogeneity by specifying the distribution of preferences following a particular distribution (e.g., normal distribution; Appendix).

In the present study, we used the management fee variable and six of the non-fee dummy variables: (1) the existence of snow patches; (2) alpine vegetation without flowers; (3) one plant species with flowers; (4) two plant species with flowers; (5) three plant species with flowers; and (6) an alternative-specific constant that reflects visitors' utility with no adaptive action toward climate change. The dummy variables related to alpine vegetation are based on the dwarf bamboo only situation. The standard deviation parameters for all the variables were first estimated assuming they are normally distributed; next, the variables for which they were not significant were treated as fixed parameters. Consequently, the variables of two and three plant species with flowers were analyzed, assuming they are normally distributed; in contrast, the distributions of other variables were fixed (i.e., nonrandom parameter) in our model. In our analysis, effect coding was applied to variables related to each type of alpine vegetation and snow patches. The effect-coded variable for each quantitative level is set to 1 when the level is present, -1 if the arbitrary reference level (status quo) is present, and 0 for all others (Bech and Gyrd-Hansen 2005; Holmes and Adamowicz 2003). Our analysis was conducted using the RPLOGIT package in Nlogit 6 (Econometric Software, Inc.).

\section{Results}

The results of a conditional logit model (i.e., base model) and a mixed logit model are presented in Table 3. Table 3 suggests that the mixed logit model is better fitted to the conditional logit model. All the estimated parameters, except for one plant species with flowers, were significantly different from zero at the $<1 \%$ level. These results indicate that because of effect coding, the absolute values of the coefficients do not have meaning, but the relative values of the coefficient have important implications (Louviere et al. 2000). The coefficient of the presence of snow patches was higher than the absence of snow patches as much as 0.500 (because the absence of snow patches was -0.250 and the presence of snow patches was 0.250 ). All vegetation variables were higher than the baseline (i.e., dwarf-bamboo-only situation). Further, the standard deviations of the coefficients of one plant species with flowers, two plant species with flowers, and three plant species with flowers are statistically significant in the mixed logit model, implying the presence of preference heterogeneities for the attributes.

The mean WTP of respondents for the presence of snow patches and all vegetation variables was calculated using the estimated results given in Table 3 and Fig. 4. The WTP for the presence of snow patches was estimated to be 6.336 USD $(-6.336$ USD is the baseline 


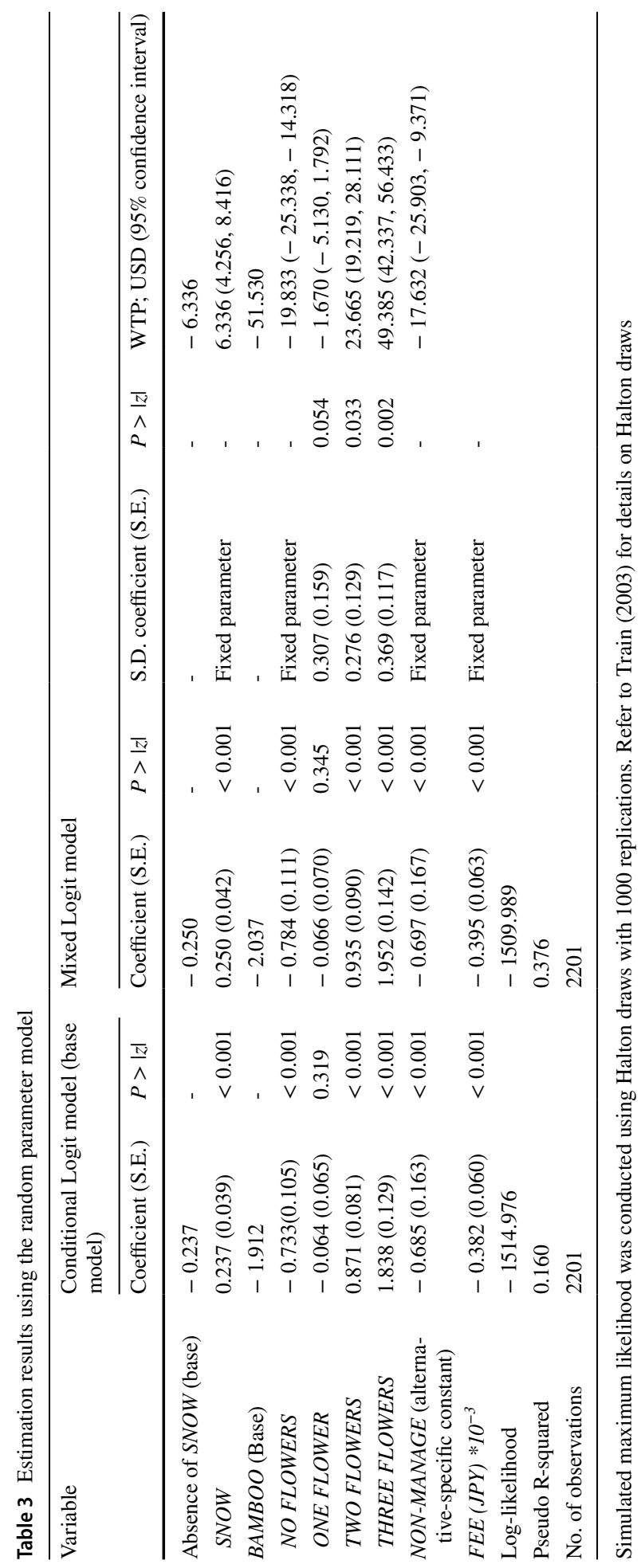




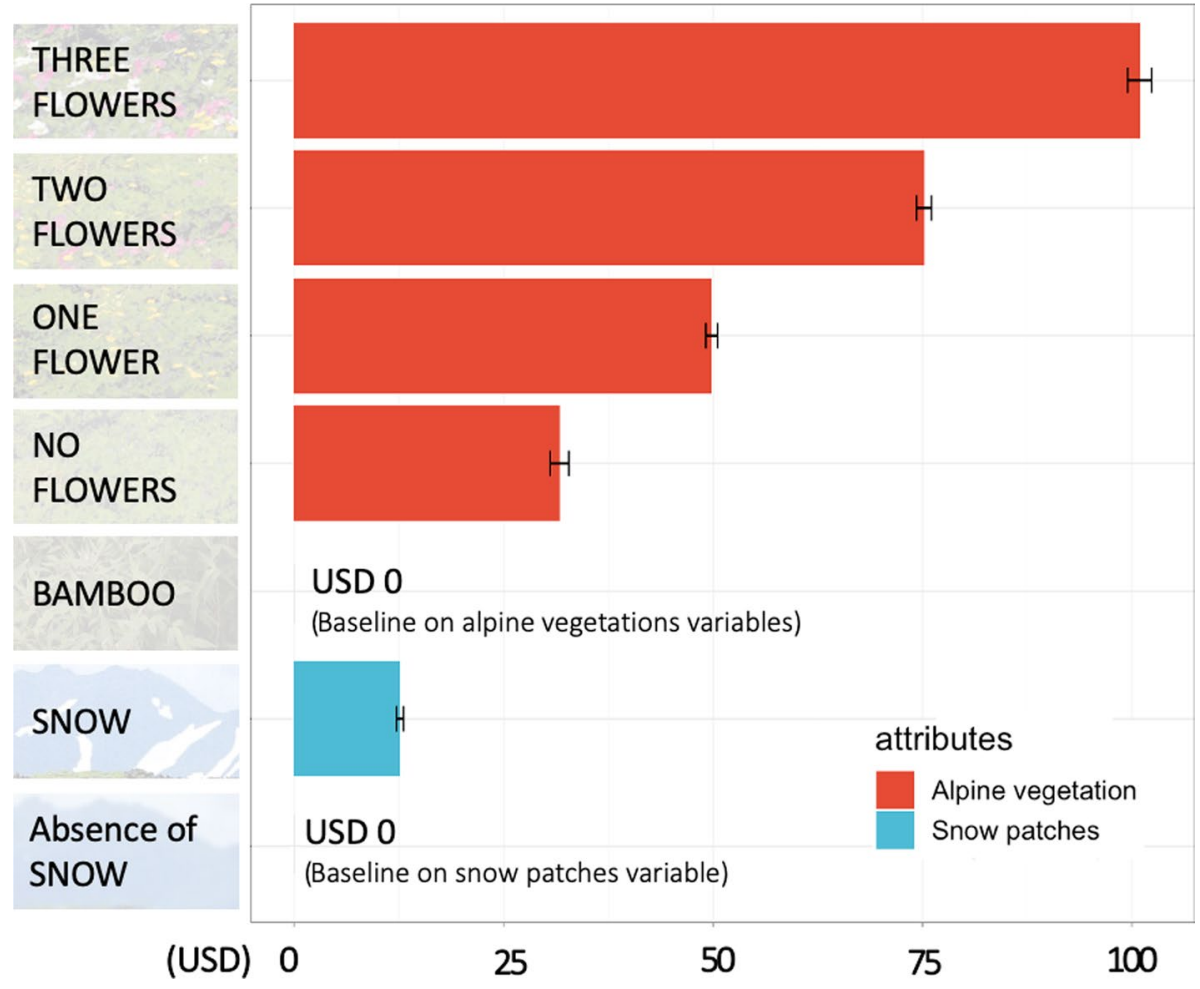

Fig. 4 Estimated mean willingness to pay (WTP) for each attribute. The WTP for snow was calculated by setting the WTP for the absence of snow as 0 . The WTPs for each attribute relating to vegetation were also calculated by setting the WTP for bamboo as 0 . The error bar represents the standard error of each attribute

level of the absence of snow patches). The WTP for the dwarf-bamboo-only situation was also estimated at - 51.530 USD. Conversely, the WTP for the three plant species with flowers (i.e., maintaining the present condition) was estimated to be 49.385 USD. Therefore, the present condition is higher than the worst-case scenario, referred to as the dwarfbamboo-only situation, as much as 100.915 USD (i.e., the difference of - 51.530 from 49.385).

\section{Discussion}

The present study explored the impacts of climate change on alpine aesthetic ecosystem services in a Japanese national park based on accumulated ecological knowledge. National parks play an important role in not only biodiversity conservation but also aesthetic landscape preservation. Moreover, the benefit of aesthetically pleasing landscapes in and around national parks contributes to the development of local socioeconomic sectors. Therefore, understanding the impact of climate change on the aesthetics of alpine landscapes is essential for environmental and park managers to develop adaptation strategies. However, little is known about the effects of climate-induced alpine landscape degradation on park visitors' 
perceptions and actions. The present study demonstrated the importance of climate change measures by presenting the resulting loss in aesthetic value in monetary terms.

Our analyses suggest that the loss of alpine wildflowers and the invasion of dwarf bamboo under climate change would cause a substantial economic loss associated with the aesthetic landscape (Fig. 4). In particular, the worst-case scenario of climate change (alpine landscapes consisting of only dwarf bamboo) substantially decreased the aesthetic value that visitors attributed to the alpine landscape, resulting in an estimated mean loss of 100.915 USD per visitor. For example, suppose that the Daisetsuzan National Park has approximately 0.07-0.1 million visitors in summer (Ministry of Environment 2021); the invasions by dwarf bamboo would reduce the social benefits associated with summer landscapes degradations by at least 7.064-10.092 million USD per year. The findings indicate sustaining the aesthetic value associated with alpine vegetations in national parks via climate change adaptation has potentially significant economic benefits. These results are also consistent with previous studies that reported that climate-induced landscape changes could have a significant negative impact on local communities (Ignacio 2017). Given the field experience of relevant studies (e.g., Kubo et al. 2018; Kudo et al. 2011), each person can eliminate $10 \mathrm{~m}^{2}$ dwarf bamboo by hand per day. Thus, the costs can be calculated based on the labor and average income in the region: about 120 USD per $10 \mathrm{~m}^{2}$ dwarf bamboo removal by hand. However, it seems unrealistic to suppose a linear increase in costs. Therefore, we leave this cost-benefit analysis for future research.

As in the present study, Rewitzer et al. (2017) who investigated preferences for alpine agricultural landscape changes also reported that the public did not prefer some landscape changes, in that case tree-line elevation and/or grassland intensification. Our results also support the findings of several studies reporting negative impacts of climate change on certain socioeconomic sectors (Burke et al. 2016; Hsiang et al. 2017; Remoundou et al. 2015), indicating the importance of adapting to the impacts of climate change in national parks (Jopp et al. 2010; Kaján and Saarinen 2013). Given that there is no correlation between preferred aesthetic services associated with forest landscapes and those associated with biodiversity (Graves et al. 2017), ways to sustain aesthetic ecosystem services in the alpine area should be developed as well as the conservation of biodiversity which previous research and actions focused on (e.g., Kudo et al. 2017).

It is noteworthy that the WTP for each dummy variable associated with alpine vegetation dropped at approximately regular intervals, with the visitors' preference for alpine landscapes containing certain numbers of wildflower species being nearly linear (Fig. 4). This finding suggests that the utility associated with the vegetation in an alpine landscape has no threshold and thus provides valuable insight into developing climate change adaptation strategies; the benefits of conserving alpine vegetation may be higher than the cost, even if some alpine species are lost and/or dwarf bamboo covers some areas. Furthermore, in our choice experiment scenario, the white flowers dominated the images, whereas the area of yellow and pink flowers was small; however, the WTP for each dummy variable associated with alpine vegetation dropped at approximately regular intervals. Thus, our results also imply that visitors' preferences for vegetated alpine landscapes are affected not by the area and/or dominance of each alpine species but by the number of species and/or flower colors. In a study of fields of wildflowers in a forest setting, Graves et al. (2017) also found that color diversity significantly affected visitors' aesthetic preferences. These results also support the importance of biodiversity conservation for aesthetic cultural services.

Snow patches also play an important role in the aesthetic services of alpine landscapes. According to our survey, the disappearance of snow patches decreased visitors' appreciation for the alpine landscape. Although the impact of the loss of snow patches on WTP was 
smaller than that of alpine vegetation, their disappearance would have a negative impact on the benefits for park visitors. Our analysis showed that visitors have a potential WTP of approximately 12.672 USD to protect snow patches (Fig. 4). It indicates that the national park might lose a minimum of approximately $0.887-1.267$ million USD per year due to the loss of snow patches in summer with the assumption that the Daisetsuzan National Park has approximately $0.07-0.1$ million visitors in summer. To date, most alpine landscape studies have focused on glaciers and have concluded that they play an important role in the aesthetics of alpine environments (Hermes et al. 2018; Schirpke et al. 2016). We found that snow patches, despite being much smaller than glaciers, are also aesthetically important to visitors. Our findings provide useful information regarding the valuation of remaining snow patches as a landscape component, and suggest that policymakers need to implement both adaptation and mitigation measures by considering how much people lose their benefits without the measures. Because global warming makes it difficult to sustain snow patches until summer (Yokohata et al. 2021), it is recommended not only to adjust the mountain-climbing season and/or tailor hiking trails for glacier tourism under climate change (Bury et al. 2011; Chevallier et al. 2011; Salim et al. 2021), but also enhance the climate change mitigation strategy.

Our analysis uncovered the heterogeneity of visitors' preferences for alpine vegetation and snow patches (Table 3). The image-based choice experiment is known to cause greater preference heterogeneity (Shr et al. 2019); however, preference heterogeneity was less for the worst-case scenario. Although most visitors did not appreciate landscapes composed of vegetation without flowers, the preference heterogeneity for better scenarios was significantly greater than zero. For example, for three plant species with flowers, the distribution of the preferences followed a normal distribution with a mean of 1.838 and variance of 0.369 . This indicates that some respondents appreciated the alpine landscape composed of some types of flowers, whereas other respondents were unwilling to pay for the preservation of the landscape much. These findings indicate that managers can easily build consensus on the need for climate change adaptation through a description of the worst-case scenario. On the other hand, the goals of climate change adaptation-whether conserving three wildflower species or two, for example-may be controversial. These results are contrary to those of a previous study that assessed the aesthetic value of flowers in forested areas (Graves et al. 2017). A possible explanation for the different results could be partly affected by the status quo bias. Our study evaluates visitor preferences based on climate change scenarios; in other words, in our choice experiment, respondents were asked to valuate future alpine landscapes with reference to the current situation. This status quo bias could have affected some respondents' preferences. Consequently, this caused preference heterogeneity. The present study, therefore, implies the importance of where to place the reference point of discussion in a changing environment particularly attributed to climate change: current state, worst-case scenario, medium scenario. For example, when environmental managers communicate about climate change adaptation strategies to citizens, they should carefully select where to place the reference point because it possibly affects public preferences for adaptation strategy goals. Our findings regarding visitors' aesthetic preferences heterogeneity provide valuable insights for environmental managers as they develop these goals.

The preferences for snow patches are not heterogeneous, meaning that the WTP of almost all respondents decreased with a decline in snow patches. Therefore, for most visitors, the presence of snow patches is important to the aesthetic value of alpine landscapes. Although snow patch conservation mostly depends on climate change mitigation strategies, park managers can adapt through measures such as the development of climbing routes to 
view the existing snow patches. Our analysis indicated that the WTP for snow patches was 12.672 USD per visitor, allowing for the development of these adaptive measures.

Finally, our study also provides important insights for addressing climate change in the alpine areas of national parks. As shown in Table 3, the coefficient of the alternativespecific constant was significantly negative, which implies that visitors' benefits decrease without measures for climate change adaptation. These decreased benefits are associated with alpine ecosystem services, and the economic loss is estimated to be approximately 17.632 USD per visitor. Although the alternative-specific constant includes some factors affecting the choice of "no adaptive management of alpine environments" (because this option was always presented as scenario 3), these results highlight the need for adaptive management for climate change in order to maintain the social benefits associated with alpine landscapes in national parks.

Although our findings should contribute to the development of adaptive management for climate change in alpine areas of national parks, there are some limitations to applying our results to actual policymaking. For instance, our target group included only domestic visitors to the national park. The Japanese government has been trying to increase the number of foreign visitors to the country's national parks, which implies that it is also important to understand foreigners' aesthetic preferences. Non-visitors (i.e., local residents and general citizens) are also important stakeholders because they too receive aesthetic benefits from alpine landscapes (Assandri et al. 2018; Schirpke et al. 2016; Yoshimura and Hiura 2017).

Furthermore, our study also includes challenges in the evaluation of the annual loss of social benefits associated with alpine aesthetic landscape degradation. Firstly, we only considered the impact of climate change on alpine landscapes in summer, and our sample includes only summer visitors. However, climate change also affects alpine landscapes in other seasons, including the timing and quality of the color change in autumn foliage (Koide et al. 2019; Liu et al. 2019). Park visitors in each season may also have different preferences for alpine landscapes. For example, the benefits for autumn visitors possibly depend on the quality of the leaf colors rather than snow patches and alpine flowers. Moreover, the aesthetic alpine ecosystem services are also available for the local residents and the general public. Thus, our result can be insufficient for the valuation of the annual economic loss associated with alpine landscapes. Therefore, future studies are required to address this issue while focusing on multiple stakeholders and different seasons.

Second, we calculated the annual economic loss associated with the alpine aesthetic landscape degradation based on the data observing only the number of visitors by using a sensor camera. To assess the economic loss more accurately, further research needs to verify the exact number of visitors and derive more detailed visitor characteristics. The use of mobile phone location data and SNS data has the potential to play a vital role in overcoming the challenges, which have been addressed in recent studies (e.g., Jaung and Carrasco 2020; Kubo et al. 2020; Sinclair et al. 2020).

Finally, there are also limitations regarding stated preference methods, including our scenario. We sincerely designed the image-based survey to focus on aesthetic value; however, the value might include other benefits, owing to the respondents' perception of images. Furthermore, although our choice experiment survey focuses on climate change adaptation strategies, we did not present detailed information about the realistic measures supported by the visitors' donations. Despite the fact that our scenario mainly addresses climate change adaptation, maintaining snow patches can be achieved using climate change mitigation measures. To understand the measures supported by visitors, further research is 
recommended to address park visitors' preferences for climate change measures, including both mitigation and adaptation strategies.

\section{Conclusions}

Our analysis revealed that park visitors prefer alpine landscapes with snow patches on mountains and some types of alpine flowers, whereas the invasion of alpine vegetation by dwarf bamboo and the disappearance of snow patches due to climate change substantially deteriorates the perceived value of the landscape. The monetary value associated with alpine flowers was estimated at approximately 100.915 USD, and that of snow patches was 12.672 USD. Suppose the number of people who visit the park each summer is approximately $0.07-0.1$ million; therefore, a total of 7.951-11.359 million USD might be lost in the local economy due to climate change-induced summer landscape degradation annually. However, since the aesthetic value associated with alpine landscapes is not exclusively enjoyed by summer visitors, that the estimated value is the minimum of the loss values. In addition, the annual economic loss without measures for climate change adaptation was estimated as 17.632 USD per visitor. Therefore, sustaining the aesthetic value of alpine landscapes in national parks via climate change adaptation has potentially significant economic benefits; the present study highlights the importance of climate change adaptation measures (Salim et al. 2021). We believe that this study contributes to the development of climate change adaptation and mitigation strategies by considering the benefits for society from ecosystems.

\section{Appendix}

In a random parameter logit model, utility $(U)$ can be described as an observable component $(V)$ and a random error component for unobservable factors $(\varepsilon)$ with independent and identically distributed assumptions (Louviere et al. 2000; McFadden 1974; Train 2009). An individual respondent $(i)$ chooses an alternative $(j)$ in period $(t)$, which maximizes utility, as shown in equation (1):

$$
\begin{gathered}
U_{i j t}=f\left(V_{i j t}, \varepsilon_{i j} t\right)=V_{i j t}+\varepsilon_{i j t} \\
V_{i j t}=\beta_{i}^{\prime} x_{i j t} \\
\beta_{i}=b+\Gamma v_{i},
\end{gathered}
$$

where $b$ is the population mean for the coefficient vector, $\nu_{i}$ is a vector of random variables that capture the individual unobserved heterogeneity, and $\Gamma$ is the nonzero elements of the lower triangular Cholesky matrix, which refers to the standard deviation of individual specific parameters around the population mean. This model can incorporate unexplained preference heterogeneity through random terms in the distributions of parameters (Hess and Rose 2009).

The alternative $j$ was chosen by individual ( $i$ ) if $U_{i j}>U_{i k}$ for all $k \neq j$. Thus, the probability that a respondent chooses the alternative $j$ from choice set $C$ is represented as follows: 


$$
\begin{aligned}
P_{i j} & =\operatorname{Pr}\left[U_{i j}>U_{i k}\right] \forall k \neq j, \forall k \in C \\
& =\operatorname{Pr}\left[V_{i j}+\varepsilon_{i j t}>V_{i k}+\varepsilon_{i k}\right] \\
& =\operatorname{Pr}\left[V_{i j}-V_{i k}>\varepsilon_{i k}-\varepsilon_{i j}\right] .
\end{aligned}
$$

If the term $\varepsilon_{i j t}$ is identically and independently distributed as the extreme value type 1 , we can calculate the expected probability that alternative $j$ was chosen by individual respondent $i$ using a multivariate probability density function $\beta$. The expected probability $\left(E_{i j}\right)$ is presented in the following equation:

$$
\begin{gathered}
E_{i}=\int L_{i} \bullet f(\beta \mid \Omega) d \beta \\
L_{i}=\frac{\exp \left(\beta_{i}^{\prime} x_{i j t}\right)}{\sum_{k \in C} \exp \left(\beta_{i}^{\prime} x_{i k t}\right)}
\end{gathered}
$$

These parameters are estimated by simulated maximum likelihood techniques that maximize the simulated log-likelihood function because the integral of estimating this model does not have a closed form (McFadden and Train 2000; Train 2009).

Acknowledgements The authors thank Ms. B. Arenna for her helpful comments on the questionnaire and for conducting the on-site survey. We appreciate the helpful comments received on an early draft presented at the 2019 Oceania Ecosystem Services forum held in Christchurch, New Zealand. We would also like to express our gratitude to the helpful comments of the journal editors and anonymous reviewers on the early drafts.

Author Contribution KM conceived and coordinated the study with TK. KM, TK, and HO developed the choice experiment survey. KM analyzed the data with YS. KM and TK contributed to funding acquisition. YS and TK contributed to supervision, reviewing, and editing. KM wrote the manuscript with contributions from TK, OH, YA, and YS.

Funding This work was supported by the Japan Society for the Promotion of Science (Nos. 19H04337, 16K00697, and Overseas Research Fellowships); Ministry of the Environment, Japan (the Environmental Economics and Policy Study); and the SOMPO Environment Foundation (Grant Program for Doctoral Course Students).

\section{Declarations}

Conflict of interest The authors declare no competing interests.

Open Access This article is licensed under a Creative Commons Attribution 4.0 International License, which permits use, sharing, adaptation, distribution and reproduction in any medium or format, as long as you give appropriate credit to the original author(s) and the source, provide a link to the Creative Commons licence, and indicate if changes were made. The images or other third party material in this article are included in the article's Creative Commons licence, unless indicated otherwise in a credit line to the material. If material is not included in the article's Creative Commons licence and your intended use is not permitted by statutory regulation or exceeds the permitted use, you will need to obtain permission directly from the copyright holder. To view a copy of this licence, visit http://creativecommons.org/licenses/by/4.0/.

\section{References}

Amagai Y, Kaneko M, Kudo G (2015) Habitat-specific responses of shoot growth and distribution of alpine dwarf-pine (Pinus pumila) to climate variation. Ecological Research 30(6):969-977. https://doi.org/10. 1007/s11284-015-1299-6 
Amagai Y, Kudo G, Sato K (2018) Changes in alpine plant communities under climate change: Dynamics of snow-meadow vegetation in northern Japan over the last 40 years. Applied Vegetation Science 21(4):561-571. https://doi.org/10.1111/avsc.12387

Assandri G, Bogliani G, Pedrini P, Brambilla M (2018) Beautiful agricultural landscapes promote cultural ecosystem services and biodiversity conservation. Agriculture, Ecosystems \& Environment 256:200210. https://doi.org/10.1016/j.agee.2018.01.012

Bateman IJ, Day BH, Jones AP, Jude S (2009) Reducing gain-loss asymmetry: a virtual reality choice experiment valuing land use change. Journal of Environmental Economics and Management 58(1):106-118. https://doi.org/10.1016/j.jeem.2008.05.003

Bech M, Gyrd-Hansen D (2005) Effects coding in discrete choice experiments. Health Economics 14(10):1079-1083. https://doi.org/10.1002/hec.984

Bliemer MCJ, Rose JM, Hensher DA (2009) Efficient stated choice experiments for estimating nested logit models. Transportation Research Part B: Methodological 43:19-35. https://doi.org/10.1016/j.trb.2008. 05.008

Burke M, Craxton M, Kolstad CD, Onda C, Allcott H, Baker E et al (2016) Opportunities for advances in climate change economics. Science 352(6283):292. https://doi.org/10.1126/science.aad9634

Bury JT, Mark BG, McKenzie JM, French A, Baraer M, Huh KI et al (2011) Glacier recession and human vulnerability in the Yanamarey watershed of the Cordillera Blanca. Climatic Change 105(1):179-206. https://doi.org/10.1007/s10584-010-9870-1

Chen H, Zhu Q, Peng C, Wu N, Wang Y, Fang X et al (2013) The impacts of climate change and human activities on biogeochemical cycles on the Qinghai-Tibetan Plateau. Global Change Biology 19(10):2940-2955. https://doi.org/10.1111/gcb.12277

Chevallier P, Pouyaud B, Suarez W, Condom T (2011) Climate change threats to environment in the tropical Andes: glaciers and water resources. Regional Environmental Change 11(1):179-187. https://doi.org/ 10.1007/s 10113-010-0177-6

Crowther TW, Todd-Brown KEO, Rowe CW, Wieder WR, Carey JC, Machmuller MB et al (2016) Quantifying global soil carbon losses in response to warming. Nature 540(7631):104-108. https://doi.org/10. 1038/nature20150

Cullen NJ, Sirguey P, Mölg T, Kaser G, Winkler M, Fitzsimons SJ (2013) A century of ice retreat on Kilimanjaro: the mapping reloaded. The Cryosphere 7(2):419-431. https://doi.org/10.5194/tc-7-419-2013

Fleischer A, Sternberg M (2006) The economic impact of global climate change on Mediterranean rangeland ecosystems: a space-for-time approach. Ecological Economics 59(3):287-295. https://doi.org/10. 1016/j.ecolecon.2005.10.016

Folkersen MV (2018) Ecosystem valuation: changing discourse in a time of climate change. Ecosystem Services 29:1-12. https://doi.org/10.1016/j.ecoser.2017.11.008

Gössling S, Scott D, Hall CM, Ceron J-P, Dubois G (2012) Consumer behaviour and demand response of tourists to climate change. Annals of Tourism Research 39(1):36-58. https://doi.org/10.1016/j.annals. 2011.11.002

Gottfried M, Pauli H, Futschik A, Akhalkatsi M, Barančok P, Benito Alonso JL et al (2012) Continent-wide response of mountain vegetation to climate change. Nature Climate Change 2(2):111-115. https://doi. org/10.1038/nclimate1329

Graves RA, Pearson SM, Turner MG (2017) Species richness alone does not predict cultural ecosystem service value. Proceedings of the National Academy of Sciences 114(14):3774. https://doi.org/10.1073/ pnas. 1701370114

Hall MHP, Fagre DB (2003) Modeled Climate-Induced Glacier Change in Glacier National Park, 18502100. BioScience 53(2):131-140. https://doi.org/10.1641/0006-3568(2003)053[0131:MCIGCI]2.0. $\mathrm{CO} ; 2$

Hanley N, Czajkowski M (2019) The role of stated preference valuation methods in understanding choices and informing policy. Review of Environmental Economics and Policy 13(2):248-266

Hensher, D.A., Rose, J.R., Greene, W.H., 2015. Applied Choice Analysis second edition. Cambridge University Press, Cambridge.

Hermes J, Albert C, von Haaren C (2018) Assessing the aesthetic quality of landscapes in Germany. Ecosystem Services 31:296-307. https://doi.org/10.1016/j.ecoser.2018.02.015

Hess S, Rose JM (2009) Should Reference Alternatives in Pivot Design SC Surveys be Treated Differently? Environmental and Resource Economics 42(3):297-317. https://doi.org/10.1007/s10640-008-9244-6

Hirao AS, Kudo G (2008) The effect of segregation of flowering time on fine-scale spatial genetic structure in an alpine-snowbed herb Primula cuneifolia. Heredity 100(4):424-430. https://doi.org/10.1038/hdy. 2008.1

Holmes, T. P., Adamowicz, W. L. (2003). Attribute-Based Methods. In P. A. Champ, K. J. Boyle, T. C. Brown (Eds.), A Primer on Nonmarket Valuation (pp. 171-219). Dordrecht: Springer Netherlands. 
Howley P (2011) Landscape aesthetics: Assessing the general publics' preferences towards rural landscapes. Ecological Economics 72(15):161-169. https://doi.org/10.1016/j.ecolecon.2011.09.026

Hsiang S, Kopp R, Jina A, Rising J, Delgado M, Mohan S et al (2017) Estimating economic damage from climate change in the United States. Science 356(6345):1362. https://doi.org/10.1126/science.aal4369

Hsee CK (1996) The evaluability hypothesis: an explanation for preference reversals between joint and separate evaluations of alternatives. Organizational Behavior and Human Decision Processes 67(3):247257. https://doi.org/10.1006/obhd.1996.0077

Huber J, Zwerina K (1996) The importance of utility balance in efficient choice designs. Journal of Marketing Research 33(3):307-317. https://doi.org/10.1177/002224379603300305

Ignacio P (2017) Climate change impacts on ecosystem services in high mountain areas: a literature review. Mountain Research and Development 37(2):179-187. https://doi.org/10.1659/MRD-JOURN AL-D-16-00110.1

Jaung W, Carrasco LR (2020) Travel cost analysis of an urban protected area and parks in Singapore: A mobile phone data application. Journal of environmental management 261:110238. https://doi.org/10. 1016/j.jenvman.2020.110238

Jopp R, DeLacy T, Mair J (2010) Developing a framework for regional destination adaptation to climate change. Current Issues in Tourism 13(6):591-605. https://doi.org/10.1080/13683501003653379

Kaján E, Saarinen J (2013) Tourism, climate change and adaptation: a review. Current Issues in Tourism 16(2):167-195. https://doi.org/10.1080/13683500.2013.774323

Kamakura W, Haaijer R, Wedel M (2001) The no-choice alternative in conjoint choice experiments. International Journal of Market Research 43(1):1-12. https://doi.org/10.1177/147078530104300 105

Koide D, Ide R, Oguma H (2019) Detection of autumn leaf phenology and color brightness from repeat photography: accurate, robust, and sensitive indexes and modeling under unstable field observations. Ecological Indicators 106:105482. https://doi.org/10.1016/j.ecolind.2019.105482

Kubo T, Uryu S, Yamano H, Tsuge T, Yamakita T, Shirayama Y (2020) Mobile phone network data reveal nationwide economic value of coastal tourism under climate change. Tourism Management 77:104010. https://doi.org/10.1016/j.tourman.2019.104010

Kubo T, Shoji Y, Tsuge T, Kuriyama K (2018) Voluntary contributions to hiking trail maintenance: Evidence from a field experiment in a national park, Japan. Ecological Economics 144:124-128. https://doi.org/10.1016/j.ecolecon.2017.07.032

Kubo T, Shoji Y (2016) Demand for bear viewing hikes: implications for balancing visitor satisfaction with safety in protected areas. Journal of outdoor recreation and tourism 16:44-49. https://doi.org/ $10.1016 /$ j.jort.2016.09.004

Kudo G (2014) Monitoring of mountain ecosystems under climate change: its significance and perspectives. Association of International Research Initiatives for Environmental Studies 19(1):3-11

Kudo G, Amagai Y, Hoshino B, Kaneko M (2011) Invasion of dwarf bamboo into alpine snow-meadows in northern Japan: pattern of expansion and impact on species diversity. Ecology and Evolution 1(1):85-96. https://doi.org/10.1002/ece3.9

Kudo G, Hirao AS (2006) Habitat-specific responses in the flowering phenology and seed set of alpine plants to climate variation: implications for global-change impacts. Population Ecology 48(1):4958. https://doi.org/10.1007/s10144-005-0242-Z

Kudo G, Kawai Y, Amagai Y, Winkler DE (2017) Degradation and recovery of an alpine plant community: experimental removal of an encroaching dwarf bamboo. Alpine Botany 127(1):75-83. https:// doi.org/10.1007/s00035-016-0178-2

Liu J, Cheng H, Jiang D, Huang L (2019) Impact of climate-related changes to the timing of autumn foliage colouration on tourism in Japan. Tourism Management 70:262-272. https://doi.org/10. 1016/j.tourman.2018.08.021

Louviere JJ, Hensher DA, Swait JD (2000) Stated choice methods: analysis and applications. Cambridge University Press, Cambridge

Martín-López B, Leister I, Lorenzo Cruz P, Palomo I, Grêt-Regamey A, Harrison PA et al (2019) Nature's contributions to people in mountains: a review. PloS one 14(6):e0217847. https://doi.org/ 10.1371/journal.pone.0217847

McFadden D (1974) The measurement of urban travel demand. Journal of Public Economics 3(4):303328. https://doi.org/10.1016/0047-2727(74)90003-6

McFadden D, Train K (2000) Mixed MNL models for discrete response. Journal of Applied Econometrics 15(5):447-470. https://doi.org/10.1002/1099-1255(200009/10)15:5<447::AID-JAE570>3.0.CO;2-1

Ministry of Environment (2021) Estimated number of visitors to Daisetsuzan National Park in 2020 (in Japanese). Retrieved at 19 January 2022 from https://www.env.go.jp/park/daisetsu/data/files/02_ r02result.pdf 
Molina JR, y Silva FR, Herrera MÁ (2016) Integrating economic landscape valuation into Mediterranean territorial planning. Environmental Science \& Policy 56:120-128. https://doi.org/10.1016/j. envsci.2015.11.010

Remoundou K, Diaz-Simal P, Koundouri P, Rulleau B (2015) Valuing climate change mitigation: A choice experiment on a coastal and marine ecosystem. Ecosystem Services 11:87-94. https://doi. org/10.1016/j.ecoser.2014.11.003

Revelt D, Train K (1998) Mixed logit with repeated choices: households' choices of appliance efficiency level. The Review of Economics and Statistics 80(4):647-657. https://doi.org/10.1162/0034653985 57735

Rewitzer S, Huber R, Grêt-Regamey A, Barkmann J (2017) Economic valuation of cultural ecosystem service changes to a landscape in the Swiss Alps. Ecosystem Services 26:197-208. https://doi.org/ 10.1016/j.ecoser.2017.06.014

Salim E, Ravanel L, Bourdeau P, Deline P (2021) Glacier tourism and climate change: effects, adaptations, and perspectives in the Alps. Regional Environmental Change 21:120. https://doi.org/10. 1007/s10113-021-01849-0

Schirpke U, Leitinger G, Tasser E, Schermer M, Steinbacher M, Tappeiner U (2013) Multiple ecosystem services of a changing Alpine landscape: past, present and future. International Journal of Biodiversity Science, Ecosystem Services \& Management 9(2):123-135. https://doi.org/10.1080/21513 732.2012 .751936

Schirpke U, Timmermann F, Tappeiner U, Tasser E (2016) Cultural ecosystem services of mountain regions: Modelling the aesthetic value. Ecological Indicators 69:78-90. https://doi.org/10.1016/j.ecoli nd.2016.04.001

Sinclair M, Mayer M, Woltering M, Ghermandi A (2020) Valuing nature-based recreation using a crowdsourced travel cost method: a comparison to onsite survey data and value transfer. Ecosystem Services 45:101165. https://doi.org/10.1016/j.ecoser.2020.101165

Scott D, Hall CM, Stefan G (2012) Tourism and climate change: impacts, adaptation and mitigation. Routledge

Scott D, Jones B, Konopek J (2007) Implications of climate and environmental change for nature-based tourism in the Canadian Rocky Mountains: a case study of Waterton Lakes National Park. Tourism Management 28(2):570-579. https://doi.org/10.1016/j.tourman.2006.04.020

Shimono Y, Watanabe M, Hirao AS, Wada N, Kudo G (2009) Morphological and genetic variations of Potentilla matsumurae (Rosaceae) between fellfield and snowbed populations. American Journal of Botany 96(4):728-737. https://doi.org/10.3732/ajb.0800242

Shr YHJ, Ready R, Orland B, Echols S (2019) How do visual representations influence survey responses? Evidence from a choice experiment on landscape attributes of green infrastructure. Ecological Economics 156:375-386. https://doi.org/10.1016/j.ecolecon.2018.10.015

Stern, N. H., Peters, S., Bakhshi, V., Bowen, A., Cameron, C., Catovsky, S., ... Edmonson, N. (2006). Stern Review: The economics of climate change (Vol. 30): Cambridge University Press, Cambridge.

Swait J, Adamowicz W (2001) The influence of task complexity on consumer choice: a latent class model of decision strategy switching. Journal of Consumer Research 28(1):135-148

Train, K. E. (2009). Discrete Choice Methods with Simulation (2 ed.). Cambridge: Cambridge University Press.

van Berkel DB, Verburg PH (2014) Spatial quantification and valuation of cultural ecosystem services in an agricultural landscape. Ecological Indicators 37:163-174. https://doi.org/10.1016/j.ecolind.2012. 06.025

van Vuuren DP, Edmonds J, Kainuma M, Riahi K, Thomson A, Hibbard K et al (2011) The representative concentration pathways: an overview. Climatic Change 109:5. https://doi.org/10.1007/ s10584-011-0148-Z

Wang S, He Y, Song X (2010) Impacts of climate warming on alpine glacier tourism and adaptive measures: A case study of Baishui Glacier No. 1 in Yulong Snow Mountain, Southwestern China. Journal of Earth Science 21(2):166-178. https://doi.org/10.1007/s12583-010-0015-2

Wang, S., Zhou, L.-Y. (2019). Integrated impacts of climate change on glacier tourism. Advances in Climate Change Research, 10(2), 71-79. 0.1016/j.accre.2019.06.006

Watson V, Becker F, de Bekker-Grob E (2017) Discrete choice experiment response rates: A meta-analysis. Health economics 26(6):810-817. https://doi.org/10.1002/hec.3354

Wessely J, Gattringer A, Guillaume F, Hülber K, Klonner G, Moser D, Dullinger S (2022) Climate warming may increase the frequency of cold-adapted haplotypes in alpine plants. Nature Climate Change 12:77-82. https://doi.org/10.1038/s41558-021-01255-8 
Winkler DE, Amagai Y, Huxman TE, Kaneko M, Kudo G (2016) Seasonal dry-down rates and high stress tolerance promote bamboo invasion above and below treeline. Plant Ecology 217(10):1219-1234. https://doi.org/10.1007/s11258-016-0649-y

Yokohata T, Iwahana G, Sone T, Saito K, Ishizaki NN, Kubo T et al (2021) Projections of surface air temperature required to sustain permafrost and importance of adaptation to climate change in the Daisetsu Mountains, Japan. Scientific Reports 11(1):15518. https://doi.org/10.1038/s41598-021-94222-4

Yoshimura N, Hiura T (2017) Demand and supply of cultural ecosystem services: Use of geotagged photos to map the aesthetic value of landscapes in Hokkaido. Ecosystem Services 24:68-78. https://doi.org/10. 1016/j.ecoser.2017.02.009

Publisher's note Springer Nature remains neutral with regard to jurisdictional claims in published maps and institutional affiliations.

\section{Authors and Affiliations}

\section{Kota Mameno ${ }^{1}$ (D) Takahiro Kubo Ta, $^{2, D} \cdot$ Hiroyuki Oguma ${ }^{2} \cdot$ Yukihiro Amagai $^{5}$. Yasushi Shoji ${ }^{6}$}

1 Department of Resource and Environmental Economics, Graduate School of Agricultural Science, Tohoku University, 468-1 Aramaki Azaaoba, Aoba Sendai, Miyagi 980-8572, Japan

2 Biodiversity Division, National Institute for Environmental Studies, Tsukuba, Japan

3 School of Anthropology and Conservation, University of Kent, Canterbury, UK

4 Department of Zoology, University of Oxford, Oxford, UK

5 Shiretoko Nature Foundation, Hokkaido, Japan

6 Research Faculty of Agriculture, Hokkaido University, Hokkaido, Japan 